\section{CPAP in Cystic Fibrosis: Is It Time to Surrender Yet?}

\section{To the editor:}

Measuring the efficacy of one airway clearance technique over another is still challenging and sometimes frustrating in an evidence-based era. We want our patients clear and intuitively we assume that what they expectorate is what we have really cleared. As Sirens caught Ulysses along his journey, respiratory therapists and physiotherapists are often tempted to believe that sputum is the best available end point of any treatment. Despite this, patients use sputum output to measure the relative effectiveness of different airway clearance regimens ${ }^{1}$ and patients' preferences continue to be a factor when introducing an airway clearance technique. ${ }^{2}$

The paper by Aquino and colleagues in the November issue of RESPIRATORY CARE ${ }^{3}$ evaluated if CPAP increases the effects of hypertonic saline on mucus clearance, sputum physical properties and expectoration in patients with cystic fibrosis (CF). Their crossover study randomized 15 patients to CPAP alone or CPAP followed by hypertonic saline aerosol. Direct cough was standardized as a series of 3 coughs on command and used as control intervention. Relying on outcome measures such as sputum volume, clearability, and wettability, Aquino et al concluded that CPAP alone did not improve sputum clearance or augment the effect of hypertonic saline.

As respiratory therapists and physiotherapists involved in the care of patients with $\mathrm{CF}$, we want to highlight 2 crucial points and report our experience, for a better interpretation of the results.

\section{Hypertonic Saline}

There is an extensive literature on the efficacy of inhaled hypertonic saline in CF. We already know that inhaled hypertonic saline improves mucociliary clearance, lung function, and quality of life in adults with $\mathrm{CF} .{ }^{4}$ Indeed, airway clearance techniques and hypertonic saline are often used in treatment sessions to enhance the rheology of mucus and thus promote mucus clearance by accelerating expiratory flow. To date the effect of the timing of inhaled hypertonic saline (before, during, and after airway clear- ance techniques) is still debated, even though the 3 studies that demonstrated the clinical efficacy of hypertonic saline have delivered it before airway clearance techniques. ${ }^{4-7}$ Therefore, this should be the only regimen recommendable. ${ }^{8}$

\section{CPAP}

CPAP is used under several conditions, and its application in CF seems to decrease dyspnea and improve inspiratory muscle function, ${ }^{9}$ increasing tidal volume and reducing breathing frequency. The rationale for CPAP as an airway clearance technique ${ }^{10}$ might rely on its splinting effects on airways, especially during expiration. The increased airway pressure during expiration is thought to prevent premature collapse and thus reduce gas trapping in the lungs. ${ }^{11}$ Theoretically, this might help mucus transport, and not sputum, making its dislocation dependent on the movement of air along the patented airways. Several studies have indicated this mechanical advantage during positive expiratory pressure (PEP) breathing, and this positive effect seems to be sustained even 45 min following treatment. ${ }^{10,12}$ However, short-term PEP breathing improves only central expiratory air flow, as measured by $\mathrm{FEV}_{1}{ }^{13}$ : indeed, mucus transport due to expiratory air flow is more efficient in the central than in the peripheral airways, which can be completely obstructed by mucus in CF. ${ }^{14}$

We know that CPAP reopens collapsed parts of the lungs as well, and obstructed areas are thought to reopen as a result of increased collateral ventilation. ${ }^{15}$ As suggested by Falk et al, ${ }^{16}$ this might occur in patients with $\mathrm{CF}$, mucus possibly being mobilized from peripheral small airways. Thus, CPAP could avoid early airways collapse, respiratory muscle fatigue, and oxygen desaturation, ${ }^{17}$ especially in advanced lung disease. Nevertheless, in our opinion, pressure alone cannot be considered a proper airway clearance technique, as presented by Aquino et al, without patient participation (eg, huff or forced expiration technique). As far as we achieve patent airways, patients need to sustain expiratory flow actively to mobilize secretions. This might happen if positive pressure is applied during the whole respiratory cycle, together with active techniques, ${ }^{18}$ and not only during the inspiratory phase alone, as previously described. ${ }^{10,17}$
However, due to the lack of data about its use in $\mathrm{CF}$ as an airway clearance technique, and considering the reported end points, we can assume that CPAP alone has the same effects as PEP on airway clearance during expiration in this sample. Outcomes such as those chosen by Aquino et al may not be suitable, since positive shortterm effects of an airway clearance technique such CPAP may not be reflected by sputum weight ${ }^{19,20}$; rather, by radio-aerosol deposition, ${ }^{19}$ lung function methods for testing distribution for ventilation, ${ }^{10}$ volume of trapped gas assessed via the ratio of residual volume to total lung capacity, ${ }^{17}$ and patient $^{\text {preference. }}{ }^{2}$

\section{Our Practice}

Twenty CF patients regularly followed at the $\mathrm{CF}$ center in Florence, Italy, have changed from PEP mask to CPAP as part of their airway clearance techniques, combining at the same time positive effects of continuous positive pressure with the active cycle of breathing technique (unpublished data). They represent the $44 \%$ of CF patients with severe flow obstruction $\left(\mathrm{FEV}_{1}\right.$ $<40 \%$ of predicted) who attend the $\mathrm{CF}$ center. In the year before starting CPAP, 40\% were chronically colonized with $\mathrm{Pseu}$ domonas aeruginosa, $15 \%$ with methicillin-resistant Staphylococcus aureus, and $15 \%$ with Burkholderia cepacia. Fifty percent were on oxygen therapy and $10 \%$ were on overnight noninvasive ventilation (NIV). When they were trained on CPAP, their mean age was 24.7 years, and on average they did 4 cycles of intravenous antibiotics per year prior to CPAP, although $52.9 \%$ had already done more than 4 cycles per year. The first reason patients initiated CPAP was oxyhemoglobin desaturation $(50 \%)$, followed by fatigue (35\%) and dyspnea (15\%) during PEP mask. At the start of CPAP, being on oxygen therapy and doing more than 4 intravenous antibiotics cycles per year were significantly associated $(P=.002)$. Moreover, when we considered time-to-exitus and time-to-lung transplantation as end points, CPAP was initiated significantly in advance, compared to NIV $(P=.01)$. Up to now, none have returned to PEP mask therapy, but, instead, have adopted CPAP as a new and helpful airway clearance technique in everyday life.

According to our practice, patients' needs are the key factor in choosing one airway 
clearance technique over another, and this change occurred in our cohort when respiratory conditions became worse, which may indicate that CPAP could constitute a "bridge to bridge" in CF.

To our knowledge, very little is known about the time constant for a lung unit and lung mechanics in $\mathrm{CF}$, especially if we have to tailor airway clearance interventions to the heterogeneous lung disease expressions in $\mathrm{CF}$ and then find appropriate outcomes. Only in the last decade have we learned about the positive effects of NIV, ${ }^{21}$ and there is still so much to discover about the respiratory care of $\mathrm{CF}$ patients. To improve efficacy and adherence, we need further research on the effects of CPAP and NIV on mucus transport in CF. While the results from Aquino and colleagues are of questionable clinical importance, due to methodological bias and inaccurate surrogate end points, they suggest a possible advantage. Respiratory physiotherapy is on the verge of a potentially exciting era in $\mathrm{CF}$, and we require a change in approach in step with the increasing complexity of the disease and the new technology available. Positive pressure, delivered via NIV or CPAP, might be a valid tool, especially in advanced lung disease, ${ }^{18,21,22}$ and it would require more attention and smarter outcomes.

\section{Simone Gambazza PT}

Cystic Fibrosis Centre

Fondazione Istituto di Ricovero e Cura a Carattere Scientifico Cà Granda Ospedale Maggiore Policlinico Milan, Italy

Sergio Zuffo MSc PT Rehabilitation Unit Azienda Ospedaliero Universitaria Meyer Florence, Italy

\section{REFERENCES}

1. Bradley JM, Moran FM, Elborn JS. Evidence for physical therapies (airway clearance and physical training) in cystic fibrosis: an overview of five Cochrane systematic reviews. Respir Med 2006;100(2):191-201.

2. Morrison L, Agnew J. Oscillating devices for airway clearance in people with cystic fibrosis. Cochrane Database Syst Rev 2009;(1):CD006842.

3. Aquino EA, Shimura F, Santos AS, Goto
DM, Coelho CC, Bicalho de Fuccio M, et al. CPAP has no effect on clearance, sputum properties, or expectorated volume in cystic fibrosis. Respir Care 2012;57(11):19141919.

4. Dentice RL, Elkins MR, Bye PT. Adults with cystic fibrosis prefer hypertonic saline before or during airway clearance techniques: a randomised crossover trial. J Physiother 2012;58(1):33-40.

5. Donaldson SH, Bennett WD, Zeman KL, Knowles MR, Tarran R, Boucher RC. Mucus clearance and lung function in cystic fibrosis with hypertonic saline. N Engl J Med 2006;354(3):241-250.

6. Elkins MR, Robinson M, Rose BR, Harbour C, Moriarty CP, Marks GB, et al. A controlled trial of long-term inhaled hypertonic saline in patients with cystic fibrosis. N Engl J Med 2006;354(3):229-240.

7. Eng PA, Morton J, Douglass JA, Riedler J, Wilson J, Robertson CF. Short-term efficacy of ultrasonically nebulized hypertonic saline in cystic fibrosis. Pediatr Pulmonol 1996;21(2):77-83.

8. Elkins M, Dentice R. Timing of hypertonic saline inhalation for cystic fibrosis. Cochrane Database Syst Rev 2012;(2):CD 008816.

9. Regnis JA, Piper AJ, Henke KG, Parker S, Bye PT, Sullivan CE. Benefits of nocturnal nasal CPAP in patients with cystic fibrosis. Chest 1994;106(6):1717-1724.

10. Placidi G, Cornacchia M, Polese G, Zanolla L, Assael BM, Braggion C. Chest physiotherapy with positive airway pressure: a pilot study of short-term effects on sputum clearance in patients with cystic fibrosis and severe airway obstruction. Respir Care 2006;51(10):1145-1153.

11. Groth S, Stafanger G, Dirksen H, Andersen JB, Falk M, Kelstrup M. Positive expiratory pressure (PEP-mask) physiotherapy improves ventilation and reduces volume of trapped gas in cystic fibrosis. Bull Eur Physiopathol Respir 1985;21(4):339-343.

12. Oberwaldner B, Evans J, Zach M. Forced expirations against a variable resistance: a new chest physiotherapy method in cystic fibrosis. Pediatr Pulmonol 1986;2(6):358 367.

13. Darbee JC, Ohtake PJ, Grant BJ, Cerny FJ. Physiologic evidence for the efficacy of positive expiratory pressure as an airway clearance technique in patients with cystic fibrosis. Phys Ther 2004;84(6):524-537.

14. van der Schans CP. Bronchial mucus transport. Respir Care 2007;52(9):1150-1156.

15. van der Schans CP, van der Mark TW, de Vries G, Piers DA, Beekhuis H, DankertRoelse JE, et al. Effect of positive expiratory pressure breathing in patients with cystic fibrosis. Thorax 1991;46(4):252-256.
16. Falk M, Kelstrup M, Andersen JB, Kinoshita T, Falk P, Støvring S, Gøthgen I. Improving the ketchup bottle method with positive expiratory pressure, PEP. A controlled study in patients with cystic fibrosis Eur J Respir Dis 1984;65(6):57-66.

17. Fauroux B, Boulé M, Lofaso F, Zérah F, Clément A, Harf A, Isabey D. Chest physiotherapy in cystic fibrosis: improved tolerance with nasal pressure support ventilation. Pediatrics 1999;103(3):E32.

18. Holland AE, Ntoumenopoulos G, Naughton MT, Wilson JW. Noninvasive ventilation assists chest physiotherapy in adults with acute exacerbations of cystic fibrosis. Tho$\operatorname{rax} 2003 ; 58(10): 880-884$.

19. Rubin BK. Designing clinical trials to evaluate mucus clearance therapy. Respir Care 2007;52(10):1348-1358.

20. Marques A, Bruton A, Barney A. Clinically useful outcomes measures for physiotherapy airway clearance techniques: a review. Phys Ther Rev 2006;11(4):299-307.

21. Flight WG, Shaw J, Johnson S, Webb AK, Jones AM, Bentley AM, Bright-Thomas RJ. Long-term non-invasive ventilation in cystic fibrosis: experience over two decades. J Cyst Fibros 2012;11(3):187-192.

DOI: $10.4187 /$ respcare. 02655

\section{The authors respond to: CPAP in Cystic Fibrosis: Is It Time to Surrender Yet?}

The authors thank Gambazza and Zuffo for their interest in our paper evaluating hypertonic saline inhalation and CPAP, alone and in combination in subjects with cystic fibrosis (CF). ${ }^{1}$ Gambazza and Zuffo are correct that there are few well controlled comparative studies of airway clearance techniques, in part due to the difficulty in masking and in meeting appropriate end points. $^{2}$ They are also correct in the observation that positive airway pressure, delivered either as positive expiratory pressure or CPAP, can maintain airway patency by moving the equal pressure point proximally in the airway: what they call airway "splinting." This would have little effect on mucus clearance, but, coupled with an effective cough, it would be expected to improve sputum clearance in the proximal airway generations. 3,4

We evaluated the effects of CPAP, rather than positive expiratory pressure therapy, as the latter is more effort dependent. In these subjects with mild to moderate CF lung disease there was no benefit from CPAP therapy over the use of hypertonic saline alone. 